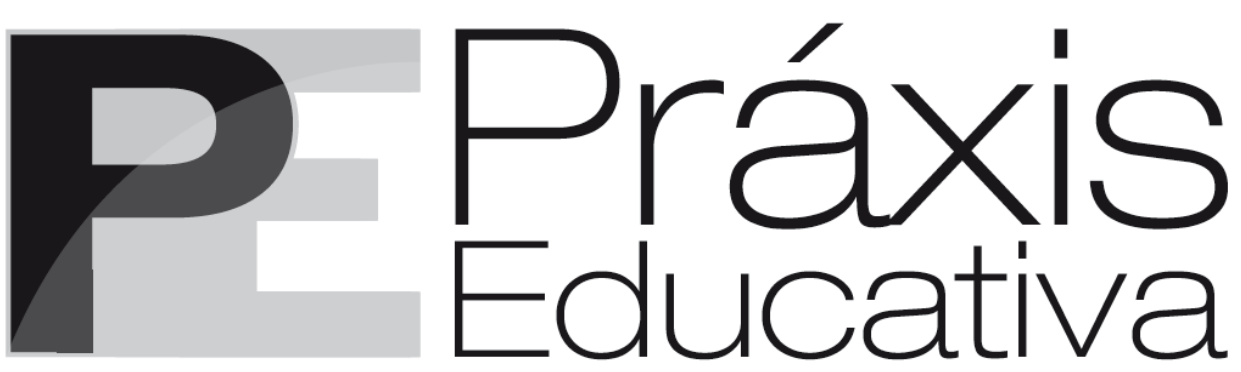

ISSN 1809-4031

elSSN 1809-4309

https://doi.org/10.5212/PraxEduc.v.16.15116.003

\title{
Reflexões sobre a precarização do trabalho docente no Ensino Superior brasileiro
}

\section{Reflections on precariousness of the teaching work in Brazilian Higher Education}

\section{Reflexiones sobre la precarización del trabajo docente en la Enseñanza Superior brasileña}

\author{
Anita Helena Schlesener* \\ (iD) https://orcid.org/0000-0003-2768-5858 \\ Michelle Fernandes Lima* \\ http:/ / orcid.org/0000-0003-0896-4747
}

\begin{abstract}
Resumo: Este artigo tem por objetivo refletir sobre a crescente precarização do trabalho docente no Ensino Superior, em contradição aos objetivos que caracterizam a Universidade: o ensino, a pesquisa e a extensão. A realização do estudo foi pautada, inicialmente, nos estudos e nas discussões sobre o neoliberalismo e a democracia, apontando limites e desafios dos docentes na luta pela conquista, na garantia de direitos e nas condições de trabalho. Ressalta-se a importância das lutas do movimento sindical docente, com destaque ao Sindicato Nacional dos Docentes das Instituições de Ensino Superior (ANDES-SN), e a necessidade de resistência. Com base nessa contextualização, são apontados aspectos referentes à precarização do trabalho docente, a partir de alguns dados referentes à realidade do trabalho de professores nas Universidades Estaduais do Paraná publicados pelo Comando Sindical Docente (CSD/ANDES/PR).
\end{abstract}

Palavras-chave: Ensino Superior. Precarização. Trabalho docente.

Abstract: This paper aims to reflect on the growing precariousness of the teaching work in Higher Education, in contradiction to the objectives that characterize the University: teaching, research and extension. The realization of the study was based, initially, on the studies and discussions on neoliberalism and democracy, pointing out the limits and challenges of professors in the struggle for conquest, in guaranteeing rights and working conditions. The importance of the struggles of the teaching union

\footnotetext{
* Doutora em História pela Universidade Federal do Paraná, Mestre em Educação: História, Política, Sociedade pela Pontifícia Universidade Católica de São Paulo. Atualmente é professora da Universidade Tuiuti do Paraná, atuando junto ao Mestrado e Doutorado em Educação. E-mail: <anitahelena1917@gmail.com>.

** Doutora em educação pela Universidade Federal do Paraná, Mestre em Educação pela Universidade Estadual de Maringá. Professora do Departamento de Pedagogia da UNICENTRO (Campus Irati), e do Programa de PósGraduação em Educação. E-mail: <mfernandeslima@yahoo.com.br>.
} 
movement is highlighted, with emphasis on the National Union of Professors of Higher Education Institutions (Sindicato Nacional dos Docentes das Instituiçōes de Ensino Superior - ANDES-SN), and the need for resistance. Based on this context, aspects referring to the precariousness of teaching work are pointed out, from some data referring to the reality of the work of professors in the State Universities of Paraná, Brazil, published by the Teachers Union Command (known in Brazil by the anacronym CSD/ANDES/PR).

Keywords: Higher Education. Precariousness. Teaching work.

Resumen: Este artículo tiene el por objetivo de reflexionar sobre la creciente precarización del trabajo docente en la Enseñanza Superior, en contradicción con los objetivos que caracterizan la Universidad: la enseñanza, la investigación y la extensión. La realización del estudio fue inicialmente basada en los estudios y en las discusiones sobre el neoliberalismo y la democracia, apuntando límites y desafíos de los docentes en la lucha por la conquista, en la garantía de derechos y en las condiciones de trabajo. Se resalta la importancia de las luchas del movimiento sindical docente, con destaque para el Sindicato Nacional de los Docentes de las Instituciones de Enseñanza Superior (ANDES), y la necesidad de resistencia. Basado en esta contextualización, son apuntados aspectos referentes a la precarización del trabajo docente, a partir de algunos datos referentes a la realidad del trabajo de profesores en las Universidades Estaduales de Paraná Brasil publicados por el Comando Sindical Docente (CSD/ANDES/PR).

Palabras clave: Enseñanza Superior. Precarización. Trabajo docente.

\section{Introdução}

Desenvolver em cada individuo bumano a cultura geral ainda indiferenciada, o poder fundamental de pensar e de saber orientar-se na vida.

(GRAMSCI, 1978, p. 1530).

A onda de conservadorismo que assola a sociedade brasileira e que se efetiva, na atualidade, em cortes na área da educação tem, entre um de seus objetivos, a abertura para a privatização das Universidades públicas brasileiras, projeto claramente sinalizado na afirmação de que nem todos precisam cursar a Universidade e que esta deve ser restrita a uma elite. Trata-se de um discurso ideológico que tem como pano de fundo o retrocesso nas políticas sociais de acesso ao ensino público e de democratização do Ensino Superior que marcaram os governos do Brasil desde 2003. Um discurso que faz parte de um projeto de instauração de uma política econômica neoliberal, que visa à ampliação da concentração de renda na fase atual de expansão do capitalismo internacional.

No Brasil, segundo dados do Censo da Educação Superior (BRASIL, 2018), existem 2.537 instituições de Ensino Superior, sendo 107 universidades públicas e 92 privadas; 13 centros universitários públicos e 217 privados; 139 faculdades públicas e 1.929 privadas; e 40 Institutos Federais e Centros Federais de Educação Tecnológica (CEFET). A expansão do Ensino Superior pela via privada, no Brasil, é marcada pelo modelo gerencial, com vistas à preparação imediata para o mercado de trabalho. É importante considerar que os processos de privatização ocorrem por diferentes vias. Pelos dados anteriores, fica evidente que a expansão do Ensino Superior, no Brasil, ocorreu pela criação de instituições privadas.

As instituições públicas concentram grande parte das pesquisas produzidas no país. No entanto, podemos observar aspectos que atingem diretamente as condições de trabalho dos docentes, como a não realização de concursos públicos; acúmulo de atividades de ensino, pesquisa e extensão; cortes nos financiamentos das pesquisas, especialmente nas áreas de Ciências Humanas e Sociais; ataque aos fundos de previdência; não cumprimento do plano de carreira dos docentes; e contratos temporários que inviabilizam as condições necessárias para a realização de atividades de ensino, pesquisa e extensão.

Esses elementos efetivam-se em um contexto que, na leitura de Boron (2001, p. 173), mostra a predominância dos "novos leviatãs", conglomerados transnacionais "[...] cuja escalada 
planetária e cuja extraordinária gravitação econômica, social e ideológica as transforma em atores políticos". Sua ação provoca um "[...] desequilíbrio irreparável no âmbito das fracas instituições e práticas democráticas das sociedades capitalistas” (BORON, 2001, p. 173). Esses novos leviatãs têm objetivos específicos quanto à educação brasileira e propõem-se a investir caso se amplie o processo de privatização já instaurado.

Como parte do processo de apropriação ampliada do capital, o conhecimento tem sido apoderado pelas grandes corporações no sentido de definir a competição comercial e a acumulação acelerada de lucros com acentuação da desigualdade social. Nesse quadro, é grave o acento dogmático que se traduz no ataque frontal à ciência, na tentativa de desacreditar e mesmo negar suas conquistas históricas, pondo em dúvida que a Terra é redonda, que a prevenção de epidemias é necessária pelo uso de vacinas, que ocorreu o holocausto, ou outros absurdos que nos fazem pensar que voltamos séculos no tempo histórico. As defesas de teorias há muito superadas pelas pesquisas científicas e reiteradas por vários dos novos governantes designados para o primeiro escalão do governo atual mostram um quadro, para alguns, hilariante, e, para outros, assustador, porque se trata de defesa dogmática e fundamentalista de crenças que não se sustentam nem no âmbito do senso comum. São discursos desconexos e sem nenhuma sustentação racional, que têm o objetivo claro de atacar os intelectuais e suas pesquisas no contexto das Universidades públicas, caracterizando-se como elemento de ataque aos docentes pesquisadores.

Devemos recordar que as Universidades públicas brasileiras são responsáveis por cerca de 90\% das pesquisas em todos os campos da ciência (ANDES-SN ${ }^{1}, 2018$ ), contribuindo com trabalhos inovadores tanto nas áreas da saúde quanto de outras tecnologias de ponta, importantes para o desenvolvimento econômico e social. Em um momento em que a inserção de novas tecnologias no mundo da produção exige a formação qualificada de trabalhadores, negar essas conquistas ou cercear o seu desenvolvimento pode ser considerado um crime contra a população brasileira. O controle ideológico aliado à defesa de uma elitização do saber fere profundamente os objetivos de superação das desigualdades sociais por via do conhecimento, sem contar que violam a Constituição de 1988 em seus princípios fundamentais, com o objetivo de restringir direitos sociais arduamente conquistados (BRASIL, 1988).

A inserção de novas tecnologias no mundo da produção exige mudanças substanciais no direcionamento do Ensino Fundamental, Médio e Superior, de modo a fazer com que a nova realidade de construção do conhecimento, articulada à internacionalização do Ensino Superior, não atue no sentido de marginalizar povos e culturas. A defesa de uma elitização do saber, aliada à sua privatização, contribui apenas para aumentar a concentração de rendas e alijar grande parcela da população dos benefícios que podem ser proporcionados pela socialização do conhecimento.

As reivindicações realizadas pelo movimento docente são fundamentais, tanto para a inserção da atividade de pesquisa no âmbito da interlocução internacional quanto para garantir a qualidade do ensino e a ampliação do acesso às classes populares, respondendo às demandas há muito colocadas pela sociedade. A defesa de um ensino de qualidade em Universidades públicas e gratuitas tem sido requisito fundamental para responder às demandas sociais por educação.

Conforme definição de publicação do Sindicato Nacional dos Docentes das Instituições de Ensino Superior - ANDES-SN (2017), a universidade pública é uma instituição voltada para a "[...] formação profissional e a reflexão crítica sobre a sociedade [...]", com o compromisso da "[...] produção do conhecimento, o desenvolvimento e a democratização do saber crítico em todas as

\footnotetext{
${ }^{1}$ ANDES-SN - Sindicato Nacional dos Docentes das Instituições de Ensino Superior.
} 
áreas da atividade humana". Para tanto, ensino, pesquisa e extensão "[...] devem ser desenvolvidos de forma equilibrada, articulada e interdisciplinar" (CADERNOS DO CEDES, 1981, p. 17).

O modo de produzir a vida no capitalismo é o modo de produzir a competição, o lucro e, consequentemente, a desigualdade social, gerando conflitos que, em algum momento, precisam ser enfrentados. O ANDES-SN é uma organização dos docentes que, ao levantar a bandeira da defesa da democracia, articula-a a outras demandas sociais como, por exemplo, o questionamento permanente das políticas neoliberais, visto que estas negam a democracia, privilegiando os interesses de grupos econômicos e de grandes corporações, às quais interessa que a relação entre Universidade e mercado se amplie.

Nessa perspectiva, a correlação de forças internas ao sindicato também se torna importante, visto que a Universidade abriga a diversidade de ideias, as lutas ideológicas que perpassam o embate político na sociedade, também na formação do Estado. Assim, conforme o momento histórico e o embate político, o movimento sindical docente enfrentou rupturas internas, mas manteve a defesa da democracia, do ensino público, da pesquisa de qualidade, embora sendo forçado, em alguns momentos, a focalizar as lutas na questão da defesa dos direitos trabalhistas dos docentes que por ele são representados.

Nesse contexto, entendemos que as lutas dos trabalhadores em educação fazem parte da resistência mais ampla pela garantia da frágil democracia conquistada a partir do movimento Diretas já, na década de 1980, e por uma Constituição que garantisse o seu fortalecimento. No cenário atual, torna-se urgente resistir às investidas dos que almejam a privatização das Universidades públicas como parte de uma luta maior pela manutenção das conquistas democráticas e pelo direito das classes populares de acesso ao Ensino Superior, bem como pela garantia da relação entre ensino, pesquisa e extensão, fundamentais para o desenvolvimento e a soberania do país.

Neste artigo, contemplamos, na próxima seção, uma reflexão sobre neoliberalismo e democracia, apontando limites e desafios dos docentes na luta pela conquista, pela garantia de direitos e pelas condições de trabalho, destacando a importância das lutas do movimento sindical docente e a necessidade de resistência. A partir dessa contextualização, apontamos aspectos referentes à precarização do trabalho docente a partir de dados e notas publicadas pelo ANDESSN, e como delimitação, contemplamos a precarização do trabalho docente nas Universidades Estaduais do Paraná a partir dos dados publicados nos sites das seções sindicais que representam os docentes.

\title{
O ideário neoliberal e a democracia: em destaque as universidades públicas
}

\author{
Nunca é licito a alguém firmar sua paz com a pobreza quando ela cai como uma
} sombra gigante sobre seu povo e sua casa.

(BENJAMIN, 1985, p. 22).

A reestruturação econômica que ocorreu a partir da década de 1970, a fim de superar a grave crise que enfrentava a economia mundial, teve como base o ideário neoliberal formulado já na década de 1940 e desenvolvido no curso dos anos. Essa reestruturação veio acompanhada de uma expansão dos mercados sem precedentes na história do capitalismo, por um lado impulsionada pela inserção de novas tecnologias e, por outro, por uma retração dos espaços públicos redefinidos por parcerias com o setor privado em expansão.

Partimos de Dardot e Laval (2016) na explicitação do ideário neoliberal como uma nova racionalidade, que se estende a todas as relações sociais e que se contrapõe frontalmente à 
democracia. A política neoliberal "[...] altera radicalmente o modo de exercício do poder governamental” (DARDOT; LAVAL, 2016, p. 189) a fim de consolidar "[...] uma subordinação a certo tipo de racionalidade política e social articulada à globalização e à financeirização do capitalismo" (DARDOT; LAVAL, 2016, p. 193). Para consolidar esses objetivos, ocorre uma forte formação do senso comum a partir de uma nova lógica normativa, novos métodos e novos objetivos que, além de reformarem o Estado, fortalecem o individualismo já disseminado como base do empreendedorismo individual. A lógica que sustenta essa política é puramente técnica e administrativa, entendendo essa perspectiva como neutra, ou seja, entendendo a política como mera administração dos recursos fiscais.

O que se destacou menos foi o caráter disciplinar desta nova política, que dá ao governo um papel de guardião das regras jurídicas, monetárias, comportamentais, atribui-lhe a função oficial de vigia das regras de concorrência no contexto de um conluio oficioso com grandes oligopólios e confere-lhe o objetivo de criar situações de mercado e formar indivíduos adaptados às lógicas de mercado (DARDOT; LAVAL, 2016, p. 191, grifo dos autores).

Os autores seguem esclarecendo as estratégias e as práticas efetivadas para concretizar esses objetivos, que implicam o fortalecimento do individualismo e da meritocracia como naturais e desvinculados do contexto de produção do social. Essa nova concepção de mundo, que visa a formar o senso comum, vem acompanhada de uma nova postura discursiva que, conforme Boron (2001, p. 179-180), desacredita a “[...] política e o espaço público: a política é o reino dos faladores, vagabundos, irresponsáveis, mentirosos e corruptos"; o público, por sua vez, é apresentado como uma "[...] esfera dominada pela ineficiência, pela irracionalidade e pela corrupção" (BORON, 2001, p. 180). Semeando o descrédito em relação à ação política, abre caminho para o aventureirismo ou para o neoconservadorismo.

Do ponto de vista ideológico, o fortalecimento dos laços familiares tradicionais e do casamento monogâmico, da religião e da fé, bem como do fundamentalismo religioso, desempenham um papel fundamental para efetivar os objetivos do capital. Embora esses hábitos representem uma educação tradicional conservadora, formam o imaginário social de modo a garantir a manutenção e a reprodução de valores importantes para a reprodução do capital.

A partir desses objetivos, a democracia como política de participação efetiva da população nas decisões e nos encaminhamentos políticos torna-se um entrave a ser superado, e isso se consegue formando o senso comum e transformando a democracia em uma máscara que oculta as mais conservadoras relações oligárquicas e autoritárias.

A esse quadro se agrega a transformação do Estado em sua atuação junto ao mercado e em defesa dos interesses da economia multinacional. Entende-se que o Estado nacional se enfraquece quanto à "soberania plena", ou seja, quanto à sua capacidade de decidir de maneira autônoma, "[...] sem condicionamentos estabelecidos por outros Estados ou entidades" (OSORIO, 2019, p. 186). Com a mundialização do capital e a expansão do sistema financeiro, os Estados nacionais, principalmente os subdesenvolvidos, dependem de empréstimos financeiros de organismos internacionais que, como condição para seus empréstimos, impõem determinadas regras de funcionamento do Estado, ditando inclusive políticas que, se não forem seguidas, resultam em pesadas sanções aos Estados devedores.

Nesse sentido, retomando a leitura de Boron (2001, p. 173), as "gigantescas empresas transnacionais", na verdade, atuam em escala mundial para dominar o conhecimento aplicado à produção e controlar a política dos Estados nacionais em torno dos quais gravitam para defender seus interesses econômicos e extrair a maior mais-valia possível. Esse controle torna-se tanto mais possível quanto aumenta o endividamento dos Estados, devastando as riquezas nacionais e levando

Práxis Educativa, Ponta Grossa, v. 16, e2115116, p. 1-17, 2021 Disponível em: < https://www.revistas2.uepg.br/index.php/praxiseducativa> 
os governos a aceitarem implementar políticas antissociais. Nesse contexto, o interesse dos mercados não coincide com os interesses da democracia. A relação entre mercado e democracia "[...] une a exclusão - econômica, social e política - estruturalmente gerada pela recomposição neoliberal do capitalismo à decadência das instituições da democracia representativa" (BORON, 2001, p. 174).

A história dos últimos 20 anos de neoliberalismo acirrou a extrema concentração de rendas por meio de novos mecanismos de extração da mais-valia e de concentração do conhecimento em favor da concentração de rendas, consequentemente lançando a maioria da população mundial na miséria e no sofrimento. Nessa perspectiva, a democracia torna-se um instrumento de mascaramento da dominação econômica, e a ideia de participação efetiva, sem a garantia de uma formação política efetiva, transforma-se meramente em mecanismo de legitimação do poder instituído.

Para Boron (2001, p. 176), a "lógica de funcionamento da democracia", mesmo de uma forma "[...] tão imperfeita como a que existe no âmbito do capitalismo, é incompatível com a que prevalece nos mercados", porque os interesses de grupos econômicos, basicamente os oligopólios, se contrapõem a interesses sociais elementares. Os interesses econômicos que prevalecem no modo de produção capitalista são extremamente excludentes. A democracia, em qualquer de suas formas, supõe uma lógica includente e participativa que não se coaduna com os interesses do mercado. Se pensarmos em soberania popular efetiva, então, temos duas perspectivas opostas e contraditórias entre si.

Conforme Boron (2001, p. 179), a vivência e a consolidação democrática implicam uma defesa da justiça como a sua grande e primeira virtude, que não se coaduna com o pressuposto da busca desenfreada do lucro econômico. A democracia tem como objetivo principal a justiça, que se traduz em uma determinada forma política incompatível com os interesses do capital.

Todos sem exceção - desde Platão até Marx, passando por Maquiavel, Hegel e Tocqueville - concordaram com um prognóstico: a democracia não pode se sustentar sobre sociedades marcadas pela desigualdade e pela exclusão social. Para que o regime democrático funcione é necessário que todas as sociedades superem um determinado limite de igualdade social, e a igualdade, como lembrava o próprio Adam Smith, deveria ser de condições e não só de oportunidades (BORON, 2001, p. 191).

O autor acentua, ainda, que o neoliberalismo não só desacredita a democracia em geral, mas "[...] é um mestre na arte de desacreditar a política e o espaço público" (BORON, 2001, p. 181). Se a democracia implica a inclusão e a justiça social, o mercado é a "esfera do egoísmo universal" (BORON, 2001, p. 181), do lucro desmesurado, não importando a quem prejudicar. De qualquer modo, a democracia funciona como máscara, “[...] o rosto político dos mercados e estes, como a face econômica" da democracia (BORON, 2001, p. 185). Enquanto esse conjunto favorece a expansão do mercado e a acumulação do capital continua a existir, nada significa a ampliação da desigualdade social e da miséria extrema.

Para Dadot e Laval (2016, grifo dos autores), “[...] é pela desmoralização que se é capaz de provocar na população a opinião de que a política do 'Estado do bem-estar' se tornou particularmente onerosa". O ideário neoliberal afirma que esse tipo de Estado destrói a "[...] honestidade, o sentido do trabalho bem feito, o esforço pessoal, a civilidade, o patriotismo" (DADOT; LAVAL, 2016, p. 210). Não é o mercado ou a acumulação exacerbada que destrói a sociedade civil, mas a falta de virtudes morais, ou seja, transfere-se para a moralidade individual a causa dos males que levam a degenerar a estrutura política e social. Aos poucos, o Estado de bemestar é substituído, no imaginário social, pela solidariedade entre parentes e viq̨inhos, transferindo toda a responsabilidade dos problemas sociais para os indivíduos.

Práxis Educativa, Ponta Grossa, v. 16, e2115116, p. 1-17, 2021 Disponível em: < https://www.revistas2.uepg.br/index.php/praxiseducativa> 
O ideário neoliberal incide, assim, na formação da subjetividade, de uma forma muito agressiva, transformando o indivíduo em alguém que se penaliza por seus fracassos. No caso das classes populares, tais fracassos são frequentes, porque a esses sujeitos não cabe o discurso da meritocracia. "O novo sujeito não é mais apenas o do círculo produção-poupança-consumo, típico de um período consumado do capitalismo" (DARDOT; LAVAL, 2016, p. 355), mas um sujeito que interioriza a culpa. Essa é uma estratégia de médio prazo para "[...] manter os indivíduos em categorias desvalorizadas", responsabilizando-os individualmente e fazendo-os "perder dignidade e autoestima" (DARDOT; LAVAL, 2016, p. 210), desestimulando a espera de auxílio social. Em nosso entender, trata-se de uma estratégia que paralisa os indivíduos, desmobiliza qualquer tentativa de organização e mobilização social e deixa-os completamente desprotegidos, contando apenas com seu esforço individual.

Nesse contexto, o Estado aparece como um arcabouço político que, a partir da racionalidade administrativa, favorece o domínio e a expansão das grandes empresas multinacionais que consolidam seu poder e seu controle dos mercados mundiais. Estendendo esse poder pelo controle do conhecimento, que é tão concentrado em alguns oligopólios, coloca em risco a vida das populações. Também se efetiva a chantagem econômica do sistema financeiro em relação aos Estados endividados, assim como a concentração do conhecimento, como dos transgênicos, dos medicamentos, da microeletrônica, das telecomunicações, etc., pode servir como mecanismo futuro de controle e exploração econômica das populações que não detêm tais conhecimentos.

Ainda conforme Boron (2001, p. 201-202), não se trata apenas do tamanho descomunal dessas empresas, mas da "[...] magnitude do desequilíbrio existente entre o dinamismo da vida econômica [...] e o frágil ou escasso desenvolvimento das instituições democráticas", ou seja, o grande desequilíbrio entre o poder econômico e a soberania popular no capitalismo. Tal situação concentra um grande poder nas mãos dos conglomerados econômicos, que gravitam em torno da política e definem os caminhos da sociedade, situação que "[...] contrasta de forma aberrante com a escassez de recursos, lentidão e ineficácia das tradicionais instituições da democracia representativa" (BORON, 2001, p. 201-202).

A grande contradição do neoliberalismo apresenta-se na formulação de Rancière (2014, p. 72), quando acentua que, na democracia, os indivíduos não podem estar "empenhados em sua felicidade privada", porque democracia implica precisamente a "luta contra esta privatização" com a ampliação da esfera pública. Do modo como se coloca, no neoliberalismo, a parceria do público e do privado, este predomina e amplia seu campo de ação em detrimento da democracia.

A pergunta que devemos colocar é qual democracia, afinal, defendemos, pois a democracia liberal, burguesa, pressupõe a separação entre economia e política, fato que permite reduzir a função do Estado a meras atividades administrativas, formais, reguladoras da vida econômica e social. Nesse contexto, o elemento fundamental encontra-se na estrutura jurídica, que reduz a política a uma série de práticas abstratas que escondem a verdadeira estrutura da sociedade: dividida, desigual, conflituosa, na ideia abstrata de igualdade para salvaguardar a ordem instituída. A democracia ampla e garantidora da participação popular efetiva exige a construção de outra estrutura econômica, social e política, expressão das lutas sociais, a ser construída no interior dessa velha ordem.

A esse contexto, agregue-se a grave crise econômica que se instalou desde 2008, atingindo os países periféricos com o mais longo processo recessivo já vivido neste início de século, com queda do Produto Interno Bruto (PIB) e aumento descomunal do desemprego. Nesses momentos, a política do bem-estar social investiria em políticas sociais no sentido de garantir a qualidade de vida dos trabalhadores, enquanto o Estado tomaria medidas de recuperação da economia com geração de novos empregos. Em outras palavras, em tempo de crise, o Estado precisa investir mais

Práxis Educativa, Ponta Grossa, v. 16, e2115116, p. 1-17, 2021 Disponível em: < https://www.revistas2.uepg.br/index.php/praxiseducativa> 
para garantir a saída da recessão. Da perspectiva neoliberal, tem-se o caminho inverso: uma política de austeridade econômica que se traduz em corte de investimentos principalmente em políticas sociais, ajustes fiscais visando ao controle das contas públicas e ao controle dos investimentos na produção e em infraestrutura, medidas que não conseguem superar a recessão (ROSSI; MELO, 2017). Para implementar tais medidas, as políticas tornam-se a cada dia mais impositivas.

No âmbito da democracia burguesa, cabe salientarmos a importância da ideologia na formação de um modo de pensar em torno da "[...] crença de que o Estado representa toda a sociedade e funciona separadamente da economia" (SCHLESENER, 2019, p. 366). Tal separação libera o mercado do controle estatal, ao mesmo tempo que permite a "[...] apropriação privada da própria estrutura do Estado que, reduzido à ideia abstrata de mero aparato administrativo e burocrático, esconde a sua real função de garantir os interesses dos grupos dominantes" (SCHLESENER, 2019, p. 368). Associa-se a ideia de democracia a sua forma parlamentar, regulamentada pela estrutura jurídica que, na leitura de Edelman (2016, p. 30-31), atua, na sociedade capitalista, no sentido restrito da "[...] expressão jurídica da força de trabalho; conhece apenas o preço do trabalho - expressão jurídica da extorsão do mais valor". O poder jurídico do capital traduz-se na "[...] dupla forma do contrato de trabalho e do direito de propriedade" (EDELMAN, 2016, p. 30-31), nada mais além disso.

Essa estrutura jurídica transforma o discurso sobre os "direitos fundamentais de todo homem" em um discurso abstrato, visto que tais direitos "[...] nunca foram concebidos para restabelecer uma igualdade entre as classes, jamais foram concebidos para a diferença" (EDELMAN, 2016, p. 75), e atuam a partir do pressuposto da garantia do direito patrimonial antes dos direitos humanos.

Dessa forma, a democracia burguesa e parlamentar, a única que vivenciamos na sociedade capitalista, tem limites que fortalecem os grupos dominantes e servem, em grande medida, para proteger seus interesses de classe. Como acentua Leher (2014, p. 3), o “[...] capital - operando também por meio do Estado - impôs transformações ainda mais profundas na educação da classe trabalhadora". Nas três últimas décadas, as lutas por uma educação pública, gratuita e de qualidade, vem perdendo terreno "[...] em prol de políticas focalizadas, referenciadas na pedagogia das competências, atributos utilitaristas que objetivam a adaptação das crianças e dos jovens ao ethos capitalista" (LEHER, 2014, p. 3).

Esses são alguns pressupostos que evidenciam a forma como as políticas para o Ensino Superior vêm sendo constituídas nos últimos anos, no contexto neoliberal traçado nesta seção. As instituições públicas passam ser consideradas gastos para o Estado, assim como os trabalhadores que nelas atuam. Esses princípios neoliberais materializam-se nos diversos ataques em relação às instituições e ao trabalho docente, cada vez mais precarizado.

Essa breve incursão no contexto do ideário neoliberal fez-se necessária para esclarecer nossa inserção no âmbito do capitalismo internacional e como suas determinações incidem sobre as reformas conservadoras propostas, que atingem diretamente o Ensino Superior e alteram a configuração das Universidades públicas na sua tarefa fundamental de unidade entre ensino, pesquisa e extensão. 


\section{Notas sobre a precarização do trabalho docente no Ensino Superior}

É próprio à sociedade que engendra classes também produzir efeitos que ocultam a real natureza delas. (COHN, 2008, p. 22).

Partimos do pressuposto de que as reformas que vêm sendo implementadas desde a década de 1990, que reconfiguram o trabalho docente no Ensino Superior, precisam ser entendidas no contexto das transformações no mundo do trabalho que ocorrem desde a década de 1970 no sistema produtivo, como meio de recuperação de mais uma crise no modo de produção capitalista, conforme tratado na seção anterior.

Assim como todo o sistema educacional, nesta fase de economia e política neoliberal, a Educação Superior tem, como uma de suas tarefas, preparar profissionais para as necessidades do mercado, função complementar àquela tradicional de produzir conhecimento, desenvolver pesquisas de ponta e cumprir os objetivos sociais da extensão. Ao lado dessa tarefa que é colocada pelos interesses da sociedade capitalista, salientamos a necessidade das classes trabalhadoras de acesso a uma formação integral, que permita a sua autonomia crítica e política. Trata-se de uma disputa que se concretiza no seio das instituições educativas, desde o Ensino Fundamental até o Ensino Superior. São esses interesses em confronto que se evidenciam na defesa da democracia, dos direitos humanos, dos direitos políticos e sociais garantidos pela Constituição, e na defesa da qualidade de ensino. Em 1995, Fernando Henrique Cardoso (FHC) afirmou:

Com a finalidade de colaborar com esse amplo trabalho que a sociedade e o Governo estão fazendo para mudar o Brasil, determinei a elaboração do "Plano Diretor da Reforma do Aparelho do Estado", que define objetivos e estabelece diretrizes para a reforma da administração pública brasileira. (CARDOSO, 1995, p. 6, grifo nosso).

Um dos problemas que o movimento sindical vem enfrentando desde a proposta do Ministério da Administração Federal e Reforma do Estado (MARE), no governo FHC, é o processo crescente de precarização do trabalho docente nas instituições públicas a partir dos frequentes cortes de investimento nas áreas de pesquisa, aumento do número de alunos em sala de aula, infraestrutura precária, contratação temporária de professores, seguindo a senda da precarização do trabalho em geral, de acordo com os objetivos da política neoliberal.

As alterações implantadas com o Regime Jurídico Único $(\mathrm{RJU})^{2}$, a introdução de novo sistema avaliativo quantificador da produção, acompanhada pela introdução de cursos de Educação a Distância (EAD), caracterizaram a reconfiguração da Universidade Pública, cujas novas ações não foram acompanhadas com o necessário investimento.

A precarização do trabalho docente no Ensino Superior incide no caráter específico de seu trabalho e de sua formação que, nesse contexto, precisa ser continuada pela elaboração de projetos e participação em grupos de pesquisa. $\mathrm{O}$ "[...] interesse destrutivo do capital tem estimulado a transformação da universidade pública, laica, gratuita e plural em um local" que serve de "[...] laboratório, sem muitos custos, para as empresas realizarem suas pesquisas" (MAUÉS; SOUZA, 2016, p. 81) e auferirem maiores lucros. A “[...] transformação do conhecimento em força produtiva e da educação em mercadoria" (MAUÉS; SOUZA, 2016, p. 81) redefine o trabalho docente e precariza todas as suas condições de produção.

\footnotetext{
2 O chamado regime jurídico único dos servidores públicos foi introduzido no direito brasileiro pela Constituição de 1988, cujo Art. 39, caput, em sua redação originária, assim dispôs: “Art. 39. A União, os Estados, o Distrito Federal e os Municípios instituirão, no âmbito de sua competência, regime jurídico único e planos de carreira para os servidores da administração pública direta, das autarquias e das fundações públicas” (ENCICLOPÉDIA JURÍDICA DA PUCSP, 2017 , n.p.).
}

Práxis Educativa, Ponta Grossa, v. 16, e2115116, p. 1-17, 2021 Disponível em: < https://www.revistas2.uepg.br/index.php/praxiseducativa> 
Para os docentes, o processo de precarização do trabalho significa não ter a perspectiva de uma carreira e, consequentemente, conviver com a incerteza de poder se dedicar à pesquisa, ao mesmo tempo que precisa responder às exigências de produzir para fortalecer o currículo, superando as precárias condições de trabalho. Essa situação atinge indiretamente os professores efetivos e temporários, a participação em grupos de pesquisa, os alunos em sala de aula, todos envolvidos em um processo de intensificação do trabalho.

No que se refere aos professores efetivos, as lutas dos últimos anos incidem diretamente na luta pela preservação do plano de carreira e a garantia de direitos já conquistados. No que concerne aos professores temporários, essa situação nem ocorre, porque seus contratos são temporários e, por vezes, inviabilizam a realização das atividades de ensino, pesquisa e extensão, além da incerteza de renovação de contratos. Esse quadro apresenta-se de formas diversas nas universidades federais e estaduais, mas algo é comum: a escassez ou até mesmo a não realização de concursos públicos fundamentada, inclusive, pela Emenda Constitucional $\mathrm{N}^{\circ}$ 95, de 15 de dezembro de 2016, que institui um novo regime fiscal por 20 anos (BRASIL, 2016).

Além das medidas restritivas direcionadas às Universidades Públicas, a Universidade e seus docentes como um todo também são afetados pela reforma trabalhista e pela terceirização, que atinge todos os professores desde a Educação Básica, e que se pretende estender ao Ensino Superior. A terceirização, no âmbito da docência, significa ser contratado por hora-aula, sem considerar o tempo de trabalho das atividades necessárias para o exercício do magistério e que se configuram em horas de trabalho não pago. O docente é contratado por tempo determinado e não mantém vínculo com seu local de trabalho, podendo ser alocado em local diferente a cada ano.

A intensificação do trabalho docente a partir da contratação por tempo determinado, sem perspectiva de renovação do contrato, transforma a atividade docente não apenas em sua forma, também em seu conteúdo, visto que, conforme acentuam Gramsci (1978) e Adorno (1986), entre outros, forma e conteúdo se relacionam intrinsecamente. A contratação de professores substitutos transforma a docência em mero ensino, sem pesquisa, podendo-se cair naquela fórmula tão conhecida da mera informação. A carreira docente, na sua articulação e indissociabilidade entre ensino, pesquisa e extensão, possibilita não apenas um ensino de qualidade, mas a integração entre universidade e sociedade, pela qual a universidade apresenta (ou devolve) para a sociedade um pouco do que aquela contribui para o funcionamento da instituição.

A implantação da terceirização no Ensino Superior passa pela revogação de leis que normatizam os vínculos dos servidores públicos e docentes com a instituição. Trata-se de subordinar o trabalho docente às formas de flexibilização do trabalho propostas pela economia neoliberal, sempre de acordo com os interesses do capital. Cabe acentuarmos que tais medidas visam a responder aos interesses do capital, tanto no processo de reforma do Estado quanto aos interesses de privatização da Universidade pública, sem considerar que tais medidas colocam em risco toda a atual estrutura pública universitária, principalmente no que se refere à unidade entre pesquisa, ensino e extensão.

A flexibilização dos processos de trabalho, que visa a incrementar o mercado e o consumo com medidas que barateiam a mão de obra, não cabem no contexto do trabalho docente, quando se tem em vista a qualidade da pesquisa e a elevação do nível de pesquisa aos padrões internacionais. Do mesmo modo, a exigência de profissionais polivalentes para mercado de trabalho, com perfis flexíveis, não se aplica ao trabalho docente que, para produzir com qualidade, precisa de muitos anos de dedicação à pesquisa.

A contratação de professores substitutos ocorreu dentro de um quadro de exigências postas pelas próprias reformas que afetaram o Ensino Superior: as reformas da previdência, 
principalmente a que se implantou no governo FHC, levou muitos docentes a solicitarem aposentadoria antecipada, a fim de garantir direitos que, com a reforma, seriam perdidos. Sem a possibilidade de novos concursos públicos ou com poucos concursos, que não supriam todas as vagas vacantes, abriu-se a nova forma de contratação por tempo determinado, conforme a Lei $\mathrm{N}^{\circ}$ 8.745, de 9 de dezembro de 1993 (BRASIL, 1993) e a Lei No 12.772, de 28 de dezembro de 2012 (BRASIL, 2012).

No conjunto, essas leis priorizam as atividades de ensino, deixando em segundo ou terceiro plano as atividades de pesquisa e extensão. Cabe acentuarmos que a precarização do trabalho docente ocorreu concomitantemente à ampliação de vagas nas disciplinas e à formação de turmas com muitos alunos. Também fica restrita a participação desses professores no sistema administrativo da Universidade e nas decisões políticas mais importantes para a instituição e para os próprios docentes. Em outras palavras, a precarização do trabalho docente e o aumento significativo de contratações temporárias atinge as atividades gerais e a instituição como um todo, visto que reconfigura a Universidade Pública, redefinindo suas funções.

Trata-se, portanto, de um problema que não se reduz à mera delimitação de contratos temporários de trabalho, mas de uma redefinição da própria estrutura da universidade pública, que incide sobre a produção e a socialização do conhecimento, expressas na indissociabilidade de pesquisa, ensino e extensão. O pressuposto dessa situação é uma nova forma de administração gerencial das universidades, condizente com a reforma estatal encaminhada pelo ideário neoliberal, e com os objetivos de elitização do conhecimento, que trazem implícita uma nova dimensão política e pedagógica do Ensino Superior.

Para apontar esse quadro crescente de precarização do trabalho docente, levantamos publicações e/ou notas sobre esses indicativos nos sites das seções sindicais dos docentes das Universidades Públicas Estaduais do Paraná. O Paraná conta com sete universidades estaduais ${ }^{3}$. As universidades têm, em seu quadro de pessoal, docentes estatutários e temporários. O plano de carreira dessas universidades é regido pela Lei No 11.713, de 7 de maio de 1997 (PARANÁ, 1997) e pela Lei No 17.382, de 6 de dezembro de 2012 (PARANÁ, 2012).

Um indicativo de precarização do trabalho docente em destaque neste artigo trata da contratação de professores temporários. No Paraná, segundo dados referentes ao quantitativo de servidores disponíveis no site da Secretaria de Estado, da Ciência, Tecnologia e Ensino Superior (SETI), em 2018, são 5.929 professores efetivos e 1.733 temporários. Com a não realização de concursos, aposentadorias e mortes, o número de professores efetivos reduz a cada ano.

Destacamos as publicações do Comando Sindical Docente (CSD), composta pelas seções sindicais docentes das Universidades Estaduais do Paraná ${ }^{4}$ sobre a precarização do trabalho docente, dispostas no Quadro 1.

\footnotetext{
${ }^{3}$ Universidade Estadual do Centro-Oeste (Unicentro), Universidade Estadual de Ponta Grossa (UEPG), Universidade Estadual de Maringá (UEM), Universidade Estadual de Londrina (UEL), Universidade Estadual do Paraná (UNESPAR), Universidade Estadual do Oeste do Paraná (UNIOESTE) e Universidade Estadual do Norte do Paraná (UENP).

${ }^{4}$ Sindicato dos Docentes da Unicentro (Adunicentro), Sindicato dos Docentes da Unioeste (Adunioeste), Seção Sindical dos Docentes da UEM (Sesduem), Seção Sindical do Andes-SN (Sindiprol/Aduel), Seção Sindical dos Docentes da Universidade Estadual de Ponta Grossa (SINDUEPG), Seção Sindical dos Docentes Universitários de Paranaguá (Sindunespar).
} 
Quadro 1 - Publicações do Comando Sindical Docente (CSD/IES/PARANÁ) referentes à precarização do trabalho docente

\begin{tabular}{|c|c|}
\hline Data & Tema \\
\hline $\begin{array}{l}24 \text { de abril } \\
\text { de } 2020\end{array}$ & $\begin{array}{l}\text { Garantia de emprego e renda para professoras (es) temporárias (os) } \\
\text { O COMANDO SINDICAL DOCENTE - CSD vem a público DENUNCIAR tais práticas e } \\
\text { COBRAR para que todas(os) as(os) professoras(es) temporárias(os) tenham a garantia de ter o seu } \\
\text { trabalho e a sua devida renda. Para passarmos por essa pandemia é necessário segurança, senso de } \\
\text { humanidade e solidariedade de classe. Por isso, conclamamos os Gestores e toda Comunidade } \\
\text { Interna das nossas IEEs a tomarem ações que permitam o mínimo de garantia para todas(os) as(os) } \\
\text { professoras(es) temporárias(os) (SESDUEM, 2020a, n.p.). }\end{array}$ \\
\hline $\begin{array}{l}25 \text { de abril } \\
\text { de } 2020\end{array}$ & $\begin{array}{l}\text { Além do arrocho salarial, Ratinho Jr acaba com progressões e promoções de servidores } \\
\text { No Paraná, o Governador, de forma sorrateira, aproveitou-se da pandemia para desferir novo ataque } \\
\text { aos servidores estaduais. Dia } 27 / 03 / 2020 \text {, emitiu o Decreto n. }{ }^{\circ} 4385 / 2020 \text {, suspendendo as } \\
\text { progressões e promoções, mesmo as já autorizadas e não implementadas (SESDUEM, 2020b, n.p.). }\end{array}$ \\
\hline $\begin{array}{l}26 \text { de maio } \\
\text { de } 2020\end{array}$ & $\begin{array}{l}\text { Não é aumento, é reposição! Sindicatos Docentes exigem reposição salarial de } \mathbf{1 7 , 5 \%} \\
\text { Os cálculos do Comando Sindical Docente, constituído por todos os sindicatos de docentes das } \\
\text { universidades públicas estaduais do Paraná, indicam que além das perdas acumuladas até abril de } \\
2020 \text { atingirem 17,5\%, cada servidor público já perdeu 5,76 salários durante este período, ou seja, } \\
\text { deixou de receber o equivalente a 5,76 meses de salários (SESDUEM, 2020c, n.p.). }\end{array}$ \\
\hline $\begin{array}{l}16 \text { de junho } \\
\text { de } 2020\end{array}$ & $\begin{array}{l}\text { Regime de trabalho temporário e precarização do trabalho docente } \\
\text { Em } 29 \text { de maio deste ano, o superintendente da SETI enviou ofício aos reitores cobrando as } \\
\text { providências para retomada das "atividades acadêmicas dos cursos de graduação", concluindo que } \\
\text { a não retomada, "ainda que de maneira remota", implicaria dentre outras consequências a não } \\
\text { renovação nem contratação de novos docentes temporários (SESDUEM, 2020d, n.p.). }\end{array}$ \\
\hline $\begin{array}{l}30 \text { de junho } \\
\text { de } 2020\end{array}$ & $\begin{array}{l}\text { CSD exige que todos os professores temporários sejam recontratados e efetivados no } \\
\text { exercício da docência superior já! } \\
\text { Os professores temporários, chamados pelo governo estadual de professores colaboradores (na } \\
\text { terminologia neoliberal), são professores que deveriam ser contratados por um processo de seleção } \\
\text { simplificado para suprir necessidades eventuais, como aposentadorias, mortes e exonerações, } \\
\text { segundo preconiza o arcabouço legal brasileiro. Entretanto, hoje, nas universidades estaduais } \\
\text { públicas do Paraná, mais de } 30 \% \text { do corpo docente é formado por professores temporários. Apesar } \\
\text { da excelente qualificação e do afinco e dedicação às atividades docentes, os professores temporários, } \\
\text { por terem contratos limitados por um período fixo (antes era de um ano, a partir de } 2019 \text { até } 6 \\
\text { meses!), são desestimulados ou até impedidos de participar de projetos de ensino, extensão e } \\
\text { pesquisa (SESDUEM, } 2020 \text { e, n.p.). }\end{array}$ \\
\hline $\begin{array}{ll}2 & \text { de } \\
\text { setembro de } \\
2020\end{array}$ & $\begin{array}{l}\text { Governador do Paraná quer congelar a carreira docente } \\
\text { PL no } 248 / 2020 \text {, tendo como proposta final o período da suspensão das progressões e promoções } \\
\text { para a carreira docente, exceto aqueles que trabalham no Hospital Universitário (SESDUEM, 2020f, } \\
\text { n.p.). }\end{array}$ \\
\hline
\end{tabular}

Fonte: Elaborado pelas autoras.

Pesquisa de Doutorado realizada por Bernardo (2020), intitulada Flexibilização contratual no setor público: condições e relações de trabalho dos professores temporários nas universidades estaduais do Paraná, levantou que, em 2002, as universidades estaduais contavam com 564 docentes com contrato temporário, e, em 2016, já eram 2.035. Segundo Boletim do CSD, com base no estudo de Bernardo (2020),

[...] na comparação entre docentes com contratos efetivos e temporários de 2002 a 2017 , ocorreu um incremento de $38,3 \%$ dos efetivos, ao passo que o dos temporários foi de $235,9 \%$. A relação entre efetivos e temporários se alterou de $11,49 \%$, em 2002, para 25,18\%, em 2016! Há diferenças entre universidades, um tipo de contrato que deveria ser exceção tornou-se algo normal nas universidades, a ponto de não poderem funcionar sem muitos deles. (SESDUEM, 2020d, n.p.).

O Quadro 1 apresenta indicativos de precarização somente em 2020 nas Universidades Estaduais do Paraná, apenas como forma de elucidar esse processo. Congelamento de promoções e progressões, não pagamento na data base e o alto número de contratos temporários, que implica

Práxis Educativa, Ponta Grossa, v. 16, e2115116, p. 1-17, 2021 Disponível em: <https://www.revistas2.uepg.br/index.php/praxiseducativa> 
contratos limitados por um período fixo, desestimulam ou até impedem esses professores de participarem de projetos de ensino, pesquisa e extensão.

Posicionarmo-nos contra a precarização do trabalho docente é uma das maneiras de lutarmos por uma Universidade Pública que seja o espaço por excelência de produção do conhecimento, aliado ao ensino e à extensão. Essa unidade é o que caracteriza a tarefa fundamental da Universidade Pública, que é não apenas produzir conhecimento para o mercado, mas socializar esse conhecimento com uma sociedade que indiretamente o financia. A terceirização, que avança em todas as áreas da produção e do consumo, não pode afetar o desempenho da Universidade na sua tarefa essencial de unir pesquisa, ensino e extensão. Por isso, mais do que defendermos a estabilidade do docente, a sua tranquilidade financeira para dedicar-se exclusivamente ao trabalho no Ensino Superior, devemos defender a democracia, com todos os direitos que garantam o bemestar social.

O contrato temporário não pode tornar-se uma prática permanente, assim como se deve banir, do âmbito da Universidade Pública, o chamado contrato intermitente. Para tanto, a crítica radical ao neoliberalismo torna-se ponto de honra: mostrar o que há de devastador para as classes trabalhadoras em geral nesse ideário e desmistificar a sua ideologia são estratégias que fazem parte da defesa da democracia.

O ANDES-SN publicou, em 2013, um dossiê nacional sobre a precarização das condições de trabalho, abrindo o debate sobre o tema, dada a importância das Universidades Públicas na construção do conhecimento e na manutenção da democracia ante a ofensiva neoliberal, empenhando-se em ampliar os mecanismos de resistência popular em defesa dos direitos instituídos (ANDES-SN, 2013). Às bandeiras já conhecidas de luta é preciso juntar, agora, a luta pela liberdade de pensamento, combatida pelo poder instituído que, no seu discurso dogmático e fundamentalista, afronta a autonomia da Universidade Pública e a sua característica fundamental, que é a garantia da diversidade de pensamento e de expressão.

O ANDES-SN, por meio de seus Congressos Nacionais e em reuniões do Conselho, esclarece as dificuldades apresentadas nas políticas públicas exaradas e incentiva a resistência quanto aos limites e às mudanças impostas por essas leis. Uma série de documentos resultantes de debates e incentivado a publicação da produção crítica sobre o tema em seus periódicos tem sido produzida pela instituição. O objetivo é abrir o debate e incentivar a resistência, a fim de assegurar condições de trabalho condizentes com a tarefa docente a cumprir, sem deixar de responder à crescente demanda por Ensino Superior e garantindo a qualidade da pesquisa.

\section{Considerações finais}

O Brasil vive uma profunda crise econômica e política, cujos desdobramentos ainda são desconhecidos. O objetivo deste artigo foi levantar algumas questões sobre o trabalho docente precarizado, partindo de uma breve contextualização das relações econômicas e políticas nacionais no contexto internacional. As mudanças nas políticas concernentes ao Ensino Superior inserem-se na dinâmica política e econômica neoliberal, implementada no país desde 1990, que reconfiguram a universidade pública no seu processo administrativo e de produção do conhecimento de acordo com os interesses da mundialização do capital. Cabe acentuarmos que tais mudanças também podem se traduzir em controle político e ideológico, situação já acenada pelos últimos governos. A partir dessa configuração, salientamos a importância do movimento sindical do Ensino Superior na defesa da democracia e dos direitos trabalhistas dos docentes. 
Uma breve incursão no contexto do ideário neoliberal fez-se necessária para esclarecer nossa inserção no contexto do capitalismo internacional. As reformas conservadoras propostas atingem diretamente o Ensino Superior e alteram a configuração das Universidades públicas na sua tarefa fundamental de unidade entre ensino, pesquisa e extensão.

O ANDES-SN tem tomado posição clara em defesa da Universidade pública e do trabalho docente de qualidade, mostrando que a defesa de direitos trabalhistas se insere na luta mais ampla em defesa da democracia, espaço político a ser garantido ante a ofensiva do capital contra o trabalho. Defendermos a democracia, embora frágil e constantemente ameaçada como a que vivemos no Brasil, é condição fundamental para avançarmos nas várias frentes de resistência e abrirmos espaço para a participação popular.

Por fim, a defesa dos direitos fundamentais e dos direitos trabalhistas, em especial, revelam o empenho em resistir às mudanças na estrutura da Universidade pública: a luta contra a precarização do trabalho docente e pela estabilidade dos docentes envolve a necessidade de garantir a indissociabilidade entre pesquisa, ensino e extensão como a forma mais viável de desenvolver uma pesquisa de qualidade. A extensão tem a máxima importância no processo de socialização dos saberes, devolvendo para a comunidade um mínimo do que ela contribui para a manutenção da Universidade pública e, ao mesmo tempo, envolver a comunidade discente com os problemas da sociedade.

A indissociabilidade entre ensino, pesquisa e extensão é fundamental para que a Universidade pública responda aos anseios e às necessidades da população que a mantém com seus impostos, principalmente com o agravamento da desigualdade social e das injustiças sociais históricas que essa população tem sofrido. A afirmação da responsabilidade do Estado na garantia do funcionamento e da expansão das Universidades públicas, bem como a preservação de sua autonomia de gestão são princípios básicos, tanto para a produção de conhecimento quanto para a qualidade do ensino e para a ampliação do acesso, tanto ao ensino quanto ao trabalho docente, que deve ser regulamentado por um regime de dedicação exclusiva a fim de garantir as prerrogativas e os objetivos dessa forma de ensino.

O grande desafio que se coloca para a Universidade pública é precisamente o de fazer aderir pensamento e realidade: a vida do pensamento precisa incidir na vida social, substituir a inércia mental, a indiferença, o que se consegue somente com a educação, que forma o pensamento autônomo. Como acentua Adorno, o ensaio, a forma de escrita que traduz essa autonomia, “[...] sacode a ilusão desse mundo simples, fundamentalmente lógico, que tão bem se coaduna à defesa daquilo que simplesmente já está ậ"' (ADORNO, 1986, p. 179). É preciso questionar o instituído, duvidar das evidências, buscar o reverso das crenças mais imediatas para descobrir o novo.

Trata-se de um processo lento, quase imperceptível, que, repentinamente, aparece na formação de "[...] um novo hábito: o de não temer o fato novo; primeiro, porque não pode ser pior de como já está; depois, porque nos convencemos de que será melhor"' (GRAMSCI, 2015, p. 203). Tendo claro que o conhecimento faz parte de uma grande disputa porque se apresenta como base para o poder instituído, cabe socializar o que se produz fazendo aderir pensamento e realidade, única maneira de construir algo novo. O conhecimento, base do sistema produtivo e da acumulação do capital, precisa ser instrumento de superação de um ensino acrítico, de uma educação voltada apenas a resultados imediatos, a fim de superarmos o ideário neoliberal com sua nova racionalidade imposta na restruturação do Estado, no caminho de uma sociedade justa e democrática. 


\section{Referências}

ADORNO, T. W. O ensaio como forma. In: ADORNO, T. W. Sociologia. São Paulo: Ática, 1986. p. 167-187.

ANDES-SN. Sindicato Nacional dos Docentes das Instituições de Ensino Superior. Cartilha: As Políticas de Desmonte da Educação Pública. ANDES-SN, jan. 2017. Disponível em: https://www.andes.org.br/sites/publicacoes/page:2. Acesso em: 12 set. 2020

ANDES-SN. Sindicato Nacional dos Docentes das Instituições de Ensino Superior. Dossiê Nacional Publicação Especial n. 03. Precarização do trabalho docente 2. ANDES-SN, nov. 2013. Disponível em: http://portal.andes.org.br/andes/print-ultimas-noticias.andes?id=9298. Acesso em: 12 set. 2020.

ANDES-SN. Sindicato Nacional dos Docentes das Instituições de Ensino Superior. Só instituições públicas fazem pesquisa no Brasil, afirma organização. ANDES-SN, 2018. Disponível em: http://portal.andes.org.br/andes/print-ultimas-noticias.andes?id=9298. Acesso em: 12 set. 2020.

BENJAMIN, W. Obras escolhidas I: Magia e técnica, arte e política. São Paulo: Brasiliense, 1985.

BERNARDO, K. A. S. Flexibilização contratual no setor público: condições e relações de trabalho dos professores temporários nas universidades estaduais do Paraná. Tese (Doutorado em Sociologia) - Universidade Federal do Paraná, Curitiba, 2020.

BORON, A. A Coruja de Minerva: mercado contra democracia no capitalismo contemporâneo. Petrópolis: Vozes, 2001.

BRASIL. [Constituição (1988)]. Constituição da República Federativa do Brasil. Brasília, DF: Senado, 1988.

BRASIL. Emenda Constitucional No 95, de 15 de dezembro de 2016. Altera o Ato das Disposições Constitucionais Transitórias, para instituir o Novo Regime Fiscal, e dá outras providências. Diário Oficial da União: seção 1, Brasília, DF, n. 241, p. 2-3, 16 dez. 2016.

BRASIL. Lei $\mathbf{N}^{\circ}$ 8.745, de 9 de dezembro de 1993. Dispõe sobre a contratação por tempo determinado para atender a necessidade temporária de excepcional interesse público, nos termos do inciso IX do art. 37 da Constituição Federal, e dá outras providências. Brasília: Presidência da República; Casa Civil, [1993]. Disponível em: http://www.planalto.gov.br/ccivil_03/leis/18745cons.htm. Acesso em: 1 set. 2020.

BRASIL. Lei N $\mathbf{N}^{\mathrm{1}}$ 12.772, de 28 de dezembro de 2012. Dispõe sobre a estruturação do Plano de Carreiras e Cargos de Magistério Federal; sobre a Carreira do Magistério Superior, de que trata a Lei n⿳⺈ 7.596, de 10 de abril de 1987; sobre o Plano de Carreira e Cargos de Magistério do Ensino Básico, Técnico e Tecnológico e sobre o Plano de Carreiras de Magistério do Ensino Básico Federal Brasília: Presidência da República; Casa Civil, [2012]. Disponível em: http://www.planalto.gov.br/ccivil_03/_ato2011-2014/2012/lei/112772.htm. Acesso em: 1 set. 2020.

BRASIL. Instituto Nacional de Estudos e Pesquisas Educacionais (Inep). Censo da Educação Superior: Sinopse Estatística - 2018. Disponível em: http://inep.gov.br/sinopses-estatisticas-daeducacao-superior. Acesso em: 1 set. 2020.

CADERNOS DO CEDES. Educação e Política: Gramsci e o problema da hegemonia. Publicado por Educação e Sociedade, n. 3. São Paulo: Cortez Editora, 1981. 
CARDOSO, F. H. Apresentação da Plano Diretor do Aparelho do Estado. In: BRASIL. Plano Diretor do Aparelho do Estado. Presidência da República, Brasília, 1995. Disponível em: http://www.bresserpereira.org.br/documents/mare/planodiretor/planodiretor.pdf. Acesso em: 10 maio 2019.

COHN, G. Apresentação à Edição Brasileira: A Sociologia como Ciência Impura. In: ADORNO, T. W. Introdução à Sociologia. São Paulo: Editora da UNESP, 2008. p. 19-34.

DARDOT, P.; LAVAL, C. A nova razão do mundo: ensaio sobre a sociedade neoliberal. São Paulo: Boitempo, 2016.

EDELMAN, B. A legalização da classe operária. São Paulo: Boitempo, 2016.

ENCICLOPÉDIA JURÍDICA DA PUCSP. Regime jurídico único. 2017. Disponível em: https://enciclopediajuridica.pucsp.br/verbete/23/edicao-1/regime-juridico-unico. Acesso em: 1 set. 2020.

GRAMSCI, A. Quaderni del carcere. Torino: Einaudi, 1978.

GRAMSCI, A. Antonio Gramsci e a Revolução Socialista: Primeiros escritos. Tradução Ana Paula Schlesener. Revista Cadernos de Pesquisa: Pensamento Educacional, Curitiba, v. 10, n. 24, p. 191-205, 2015. Disponível em: http://universidade tuiuti.utp.br/Cadernos_de_Pesquisa/pdfs/cad_pesq_24/art_10.pdf. Acesso em: 10 maio 2019.

LEHER, R. Organização, estratégia politica e o Plano Nacional de Educação. Marxismo21.org, 2014. Disponível em: https://bit.ly/3k8quwG. Acesso em: 10 set. 2019.

MAUÉS, O. C.; SOUZA, M. B. Precarização do trabalho docente na Educação Superior e os impactos na formação. Em Aberto, Brasília, v. 29, n. 97, p. 73-85, set./dez. 2016. DOI: http://dx.doi.org/10.24109/2176-6673.emaberto.29i97.\%25p

OSORIO, J. O Estado no centro da mundialização. São Paulo: Expressão Popular, 2019.

PARANÁ. Lei No 11.713, de 07 de maio de 1997. Dispõe sobre as Carreiras do Pessoal Docente e Técnico-Administrativo das Instituições de Ensino Superior do Estado do Paraná e adota outras providências. Curitiba: Casa Civil - Sistema Estadual de Legislação, [1997]. Disponível em: https://www.legislacao.pr.gov.br/legislacao/pesquisarAto.do?action=exibir\&codAto $=5808 \&$ cod ItemAto=39491. Acesso em 12 set. 2020.

PARANÁ. Lei $\mathbf{N}^{\mathbf{0}} \mathbf{1 7 . 3 8 2}$, de 06 de dezembro de 2012. Altera os dispositivos que especifica da Lei $\mathrm{n}^{\circ}$ 11.713/97, observadas as alterações da Lei $\mathrm{n}^{\circ}$ 15.050/06. Curitiba: Casa Civil - Sistema Estadual de Legislação, [2012]. Disponível em: https://www.legislacao.pr.gov.br/legislacao/pesquisarAto.do?action=exibir\&codAto $=83148$.

Acesso em: 12 set. 2020.

PARANÁ. Secretaria de Estado, da Ciência, Tecnologia e Ensino superior. Cursos oferecidos e alunos matriculados por instituição de Ensino Superior do Estado do Paraná - em dez/2018. SETI, 2018.

Disponível

em:

http://www.seti.pr.gov.br/sites/default/arquivos_restritos/files/documento/2019-

09/censo_ensino_superior_2018.pdf. Acesso em: 12 set. 2020.

RANCIÈRE, J. O ódio à democracia. São Paulo: Boitempo, 2014. 
ROSSI, P.; MELO, G. Choque recessivo e a maior crise da história: a economia brasileira em marcha ré. CECON-IE/UNICAMP, abr. 2017. Disponível em: https://bit.ly/2RmakUh. Acesso em: 1 ago. 2020.

SCHLESENER, A. H. "Esta mesa redonda é quadrada": a gestão democrática no contexto da democracia burguesa. Práxis Educativa, Ponta Grossa, v. 14, n. 1, p. 362-376, jan./abr. 2019. DOI: https://doi.org/10.5212/PraxEduc.v.14n1.019

SESDUEM. Seção Sindical dos Docentes da UEM. Garantia de emprego e renda para professoras(es) temporárias(os). SESDUEM, 24 abr. 2020a. Disponível em: http://www.sesduem.com.br/2020/04/24/garantia-de-emprego-e-renda-para-professorasestemporariasos/. Acesso em: 12 set. 2020.

SESDUEM. Seção Sindical dos Docentes da UEM. Além do arrocho salarial, Ratinho Jr acaba com progressões e promoções de servidores. SESDUEM, 25 abr. 2020b. Disponível em: http://www.sesduem.com.br/2020/04/25/alem-do-arrocho-salarial-ratinho-jr-acaba-comprogressoes-e-promocoes-de-servidores/. Acesso em: 12 set. 2020.

SESDUEM. Seção Sindical dos Docentes da UEM. Além do arrocho salarial, Ratinho Jr acaba com progressões e promoções de servidores. SESDUEM, 26 maio 2020c. Disponível em: http://www.sesduem.com.br/2020/05/26/nao-e-aumento-e-reposicao-sindicatos-docentesexigem-reposicao-salarial-de-175/. Acesso em: 12 set. 2020.

SESDUEM. Seção Sindical dos Docentes da UEM. Regime de trabalho temporário e precarização do trabalho docente. SESDUEM, 16 jun. 2020d. Disponível em: http://www.sesduem.com.br/2020/06/16/regime-de-trabalho-temporario-e-precarizacao-dotrabalho-docente/. Acesso em: 12 set. 2020.

SESDUEM. Seção Sindical dos Docentes da UEM. CSD exige que todos os professores temporários sejam recontratados e efetivados no exercício da docência superior já! SESDUEM, 30 jun. 2020e. Disponível em: http://www.sesduem.com.br/2020/06/30/csd-exige-que-todosos-professores-temporarios-sejam-recontratados-e-efetivados-no-exercicio-da-docencia-superiorja/. Acesso em: 12 set. 2020.

SESDUEM. Seção Sindical dos Docentes da UEM. Governador do Paraná quer congelar a carreira docente. SESDUEM, 2 set. 2020f. Disponível em: http://www.sesduem.com.br/2020/09/02/boletim-sesduem-governador-do-parana-quercongelar-a-carreira-docente/. Acesso em: 12 set. 2020.

Recebido em 08/04/2020

Versão corrigida recebida em 12/09/2020

Aceito em 14/09/2020

Publicado online em 10/10/2020

Práxis Educativa, Ponta Grossa, v. 16, e2115116, p. 1-17, 2021 